\title{
Different Presynaptic Roles of Synapsins at Excitatory and Inhibitory Synapses
}

\author{
Daniel Gitler, ${ }^{1}$ Yoshiko Takagishi, ${ }^{3}$ Jian Feng, ${ }^{4,5}$ Yong Ren, ${ }^{5}$ Ramona M. Rodriguiz, ${ }^{2}$ William C. Wetsel, ${ }^{2}$ \\ Paul Greengard, ${ }^{4}$ and George J. Augustine ${ }^{1}$ \\ ${ }^{1}$ Department of Neurobiology and ${ }^{2}$ Departments of Psychiatry and Behavioral Sciences, Medicine, and Cell Biology, Duke University Medical Center, \\ Durham, North Carolina 27710, ${ }^{3}$ Research Institute of Environmental Medicine, Nagoya University, Nagoya 464-8601, Japan, ${ }^{4}$ Laboratory of Molecular and \\ Cellular Neuroscience, The Rockefeller University, New York, New York 10021, and ${ }^{5}$ Department of Physiology and Biophysics, State University of New \\ York, Buffalo, New York 14214
}

The functions of synapsins were examined by characterizing the phenotype of mice in which all three synapsin genes were knocked out. Although these triple knock-out mice were viable and had normal brain anatomy, they exhibited a number of behavioral defects. Synaptic transmission was altered in cultured neurons from the hippocampus of knock-out mice. At excitatory synapses, loss of synapsins did not affect basal transmission evoked by single stimuli but caused a threefold increase in the rate of synaptic depression during trains of stimuli. This suggests that synapsins regulate the reserve pool of synaptic vesicles. This possibility was examined further by measuring synaptic vesicle density in living neurons transfected with green fluorescent protein-tagged synaptobrevin 2, a marker of synaptic vesicles. The relative amount of fluorescent synaptobrevin was substantially lower at synapses of knock-out neurons than of wild-type neurons. Electron microscopy also revealed a parallel reduction in the number of vesicles in the reserve pool of vesicles $>150 \mathrm{~nm}$ away from the active zone at excitatory synapses. Thus, synapsins are required for maintaining vesicles in the reserve pool at excitatory synapses. In contrast, basal transmission at inhibitory synapses was reduced by loss of synapsins, but the kinetics of synaptic depression were unaffected. In these terminals, there was a mild reduction in the total number of synaptic vesicles, but this was not restricted to the reserve pool of vesicles. Thus, synapsins maintain the reserve pool of glutamatergic vesicles but regulate the size of the readily releasable pool of GABAergic vesicles.

Key words: exocytosis; presynaptic; synapsin; synaptic depression; facilitation; synaptic vesicle; synaptic transmission; reserve pool

\section{Introduction}

The synapsins are abundant phosphoproteins associated with the membranes of synaptic vesicles (Greengard et al., 1993; Hilfiker et al., 1999). Three mammalian synapsin genes have been identified, with alternative splicing creating at least eight different neuronal synapsin isoforms (Südhof et al., 1989; Kao et al., 1999; Porton et al., 1999). The functions of synapsins are not clear. Synapsins have been postulated to recruit synaptic vesicles to a reserve pool (RP) (Li et al., 1995; Hilfiker et al., 1999), to regulate the kinetics of membrane fusion (Hilfiker et al., 1998; Humeau et

\footnotetext{
Received Sept. 13, 2004; revised Nov. 4, 2004; accepted Nov. 5, 2004.

This work was supported by National Institute of Mental Health Grants MH-39327 and MH-67044. D.G. was a European Molecular Biology Organization Postdoctoral Fellow and a Pfizer Fellow of the Life Science Research Foundation. R.M.R. was an American Psychological Association Minority Postdoctoral Fellow in Neuroscience. We thankF. Santamaria for help with EM image analysis software, W. Drake for assisting with EM image analysis, N. Cant for assisting with histology, U. Ashery and J. Wesseling for helpful discussions, T. Dresbach for providing DNA for GFP-tagged synaptobrevin, B. Scalettar and A. Jeromin for providing DNA for GFP-tagged synaptophysin, and S. Hilfiker, J. Jovanovic, Y. Li, T. Sihra, and C. Villalba for their comments on this manuscript.

Correspondence should be addressed to George J. Augustine, Department of Neurobiology, Duke University Medical Center, Box 3209, Durham, NC 27710. E-mail: georgea@neuro.duke.edu.

D. Gitler's present address: Department of Neurophysiology, Carl Ludwig Institute for Physiology, Leipzig University, 04103 Leipzig, Germany.

DOI:10.1523/JNEUROSCI.3795-04.2004

Copyright $\odot 2004$ Society for Neuroscience $\quad 0270-6474 / 04 / 2411368-13 \$ 15.00 / 0$
}

al., 2001), to stabilize synaptic vesicles (Rosahl et al., 1995), and/or to regulate late steps of endocytosis (Bloom et al., 2003).

One reason why it has been difficult to assign precise roles to synapsins is that interfering with synapsins with various experimental procedures has yielded different effects on synaptic function. Acute interference with synapsins at the squid giant synapse, by microinjecting synapsin-derived peptides or dephosphorylated synapsin, inhibits basal synaptic transmission, indicating a role for synapsins in neurotransmitter release (Llinas et al., 1985, 1991; Hilfiker et al., 1998). Injecting synapsin peptides or antisynapsin antibodies also changes the kinetics of postsynaptic currents, suggesting that synapsin specifically regulates the fusion of synaptic vesicles with the presynaptic plasma membrane (Hilfiker et al., 1998; Humeau et al., 2001). In contrast, deletion of the only synapsin gene in Drosophila reportedly causes no measurable change in synaptic transmission (Godenschwege et al., 2004). Genetic deletion of individual synapsin genes in mice also does not eliminate synaptic transmission. None of these deletions produces a lethal phenotype, and effects on basal synaptic transmission, where measured, are reported to be small. Deletion of synapsin I decreases glutamate release during prolonged depolarization of synaptosomes, increases facilitation at excitatory synapses, and decreases transmission at inhibitory synapses (Rosahl et al., 1993, 1995; Li et al., 1995; Terada et al., 1999). Deletion of 
synapsin II (or of both I and II) apparently does not affect the amount of transmitter released by individual action potentials, as assessed by examining synaptic facilitation, but does accelerate synaptic depression and increases post-tetanic potentiation (Rosahl et al., 1995). Finally, deletion of synapsin III decreases basal transmission at inhibitory synapses but not excitatory synapses (Feng et al., 2002).

Some of the uncertainty concerning synapsin functions is attributable to the fact that mammals possess multiple synapsin genes. If only one or two of these three genes are deleted, the remaining gene products may compensate for the missing synapsins and mask a more fundamental phenotype. To determine whether this was the case, we examined synaptic transmission in mice in which all three known synapsin genes were deleted. Furthermore, we used direct measurements of quantal content to measure basal transmitter release at excitatory and inhibitory synapses. We found that loss of all three synapsin genes was not lethal but did cause substantial changes in behavior and synaptic transmission. These defects differ for excitatory and inhibitory synapses, indicating that synapsins have unique functions at different synapses.

\section{Materials and Methods}

Generation of synapsin triple knock-out mice. Homozygous synapsin triple knock-out (TKO) mice and matching triple wild-type (TWT) mice were derived by serially breeding previously generated synapsin I (Chin et al., 1995), synapsin II (Ferreira et al., 1998), and synapsin III (Feng et al., 2002) single knock-out mice, in this order. For genotyping, tail DNA was extracted and analyzed by PCR. We used three primers that anneal to the targeting vector, to the targeted sequence, and to the surrounding genomic DNA: synapsin I sense, AGGGAGTTTCGTTACTACAGGTCC; synapsin I antisense, AGATTGGCCATGAAGTTGCTGTCC; synapsin II sense, TTCAGGTCTCAGCATACAAGGTGC; synapsin II antisense, GGAAGTTCATCATCTGGCTTGAGG; synapsin I/II targeting vector antisense, CTACTTCCATTTGTCACGTCCTGC; synapsin III sense, GTCTAGAGCAGAGTTGAACCTGTG; synapsin III antisense, CCGCCCTGGATGTTAAGATCAGAT; synapsin III targeting vector sense, ACACTGCTCGACATTGGGTGGAAA.

Two to four mice were housed in each cage in a humidity- and temperature-controlled room, under a 14/10 hr light/dark cycle, and were provided with standard laboratory chow and water ad libitum. All experiments were conducted in accordance with National Institutes of Health guidelines and with animal protocols approved by the investigators' institutional animal care and use committees.

Western blots. Antibodies against synaptotagmin, syntaxin, synaptophysin, and $\alpha$-tubulin were purchased from Sigma (St. Louis, MO). Antisynaptobrevin 2 antibodies were a generous gift from R. Jahn (MaxPlanck-Institute for Biophysical Chemistry, Göttingen, Germany). Antibodies against the NMDA receptor (NR) subunits were from Upstate Biotechnology (Lake placid, NY). Anti-postsynaptic density-95 (PSD-95) was from Affinity Bioreagents (Golden, CO). Anti-synapsin I clone 8 was from BD Transduction Labs (San Diego, CA). Anti-synapsin II was from Stressgen (San Diego, CA). Anti-synapsin III (RU486) was generated previously (Feng et al., 2002).

Whole brains were homogenized in a $1 \%$ SDS solution and boiled for 5 min. Protein concentration was measured by the DC Protein Assay kit (Bio-Rad, Hercules, CA). Equal amounts of total proteins from triple wild-type and triple knock-out mice were separated on 7.5 or $12 \%$ polyacrylamide gels and transferred to nitrocellulose membranes (Amersham Biosciences, Piscataway, NJ) for Western blot analyses. Blots were incubated sequentially with primary and HRP-conjugated secondary antisera and developed using the ECL detection method according to the manufacturer's protocol (Amersham Biosciences).

Culture and transfection. Hippocampal neurons were cultured from newborn pups (postnatal days 0-2) and transfected as described previously (Gitler et al., 2004). Microisland cultures of hippocampal neurons were prepared as described (Nishiki and Augustine, 2004). Neurons were allowed to mature for 7-14 d.

Histology. Cytochrome oxidase staining of brain sections was performed essentially as described in Wong-Riley (1979). Mice were anesthetized and transcardially perfused with $0.9 \%$ saline, followed by icecold $4 \%$ paraformaldehyde in $0.1 \mathrm{M} \mathrm{PBS,} \mathrm{pH} \mathrm{7.4} \mathrm{(Sigma).} \mathrm{The} \mathrm{heads} \mathrm{were}$ postfixed overnight, and the brain was removed and incubated in cold $30 \%$ sucrose in PBS until sectioned. Brains were sectioned sagittally at a thickness of $40 \mu \mathrm{m}$ in a sliding microtome (American Optical) and stained in a $0.1 \mathrm{~m}$ phosphate buffer solution containing $4 \%$ sucrose, 0.025 $\mu \mathrm{g} / \mathrm{ml}$ cytochrome $c$ (Sigma), and $0.5 \mathrm{mg} / \mathrm{ml}$ diaminobenzidine (Sigma). Sections were mounted on gelatin-coated slides, dehydrated by serial ethanol solutions, cleared with xylene, and coverslipped with Permount (Fisher Scientific, Hampton, NH).

Electrophysiological acquisition and data analysis. Whole-cell patchclamp recordings were made from single neurons on microislands, as described in Nishiki and Augustine (2004). Patch pipettes (2.5-4 M $\Omega$ ) were filled with intracellular solution containing (in $\mathrm{mm}$ ): 50 K-glutamate, $71 \mathrm{~K}$-gluconate (Fluka, Buchs, Switzerland), $15 \mathrm{NaCl}, 6$ $\mathrm{MgCl}_{2}$, 2 EGTA, $5 \mathrm{Na}_{2} \mathrm{ATP}, 0.3 \mathrm{Na}_{2} \mathrm{GTP}$, and 20 HEPES-KOH, pH 7.3 (285 mOsm). The extracellular solution contained (in mM): $150 \mathrm{NaCl}, 3$ $\mathrm{KCl}, 2 \mathrm{CaCl}_{2}, 2 \mathrm{MgCl}_{2}, 20$ glucose, and 10 HEPES-NaOH, pH 7.3 (310 $\mathrm{mOsm}$ ). All materials were from Sigma, unless specified otherwise. Neurons were voltage clamped at $-70 \mathrm{mV}$ with a HEKA EPC-9D amplifier (HEKA, Lambrecht/Pfalz, Germany). All experiments were performed at room temperature $\left(\sim 25^{\circ} \mathrm{C}\right)$. Electrophysiological data were sampled at $25 \mathrm{kHz}$ and filtered at $10 \mathrm{kHz}$. Axonal action potentials were evoked by depolarizing the cell body to $+40 \mathrm{mV}$ for $0.5 \mathrm{msec}$ every $15 \mathrm{sec}$, unless specified otherwise. Only cells with series resistances of $<20 \mathrm{M} \Omega$ were analyzed (typically $\sim 10 \mathrm{M} \Omega$ ), with $50 \%$ of this resistance compensated electronically. In each cell, we recorded evoked and spontaneous synaptic currents, responses to pairs of stimuli, and sustained trains of stimuli. Only a single train was evoked in each neuron to avoid eliciting longterm forms of synaptic plasticity.

To calculate the peak current and the charge transfer during a train, we first subtracted an averaged trace containing the stimulus and the action potential current but lacking any discernable synaptic currents (i.e., synaptic failures). Such traces were easily identified toward the end of a train of stimuli, when synaptic depression was maximal. We integrated the current during each trace, discarding the stimulus and action potential, and then summed the charge for the whole train. For each event in a train, the baseline was defined as the final value of current during the preceding event. In the case of excitatory events, the synaptic currents were well separated temporally, so that little summation occurred; however, because inhibitory synaptic currents decay slowly, these responses summed to a significant extent, necessitating the baseline subtraction procedure described above when calculating peak currents. Spontaneous synaptic events were semiautomatically analyzed using the MiniAnalysis program (Synaptosoft, Decatur, GA). Values were compared by the Student's $t$ test, and error bars shown in the figures indicate the SEM.

Microscopy and fluorescence imaging. Cultured cells were imaged as described in Gitler et al. (2004). Images were recorded with a Coolsnap FX CCD camera (Roper Scientific, Trenton, NJ) and acquired and processed with ISEE software (ISEE Imaging Systems, Raleigh, NC). Measurements of synaptobrevin 2 targeting were performed as described previously for synapsins (Gitler et al., 2004), except that the neurons were cotransfected with pDsRed ${ }_{2} \mathrm{Cl}$ (Clontech, Palo Alto, CA) and a green fluorescent protein (GFP)-synaptobrevin 2 construct based on the pEGFPC1 mammalian expression vector (a kind gift of Thomas Dresbach, Magdeberg, Germany). For the purpose of counting synapses, we cotransfected the cells with pDsRed ${ }_{2} \mathrm{C} 1$ and with a pcDNA3 vector encoding the synaptophysin I-GFP fusion protein (kindly provided by Bethe Scalettar, Lewis and Clark College, Portland, OR, and Andreas Jeromin, Baylor College of Medicine, Houston, TX). Transfected neurons that were spatially isolated from other transfected neurons were photographed in their entirety using a $20 \times$ UApo 0.75 numerical aperture objective. The red channel of the image was used to merge the partial images into a composite picture, using the semiautomatic photomerge option of Photoshop Elements (Adobe Systems, San Jose, CA). Hence- 
forth, a segmenting algorithm was implemented by combining elements of the ISEE software package. The green channel, containing the synaptophysin-GFP images, was clipped using the red channel as a mask. To identify the synaptic terminals, we iteratively applied successively increasing thresholds, thus segmenting the image into objects. Morphological criteria were applied to the objects to reject those that could not be synaptic terminals (by size, roundness, and aspect ratio). The number of positively identified objects was counted by resegmenting the image containing the accumulated objects.

Electron microscopy. Cells were grown on Aclar film (Nisshin EM, Tokyo, Japan) for $19 \mathrm{~d}$ and fixed with $2.5 \%$ glutaraldehyde and $2 \%$ paraformaldehyde in $0.1 \mathrm{M}$ phosphate buffer (PB) for 15-30 min. After washing in $0.1 \mathrm{M} \mathrm{PB}$ containing $4.5 \%$ sucrose, they were postfixed with $1.0 \% \mathrm{OsO}_{4}$ in $0.1 \mathrm{~m} \mathrm{~PB}$ containing $4.5 \%$ sucrose for $1 \mathrm{hr}$. They were then dehydrated in ethanol and embedded in epoxy resin. Ultrathin sections were prepared and examined with a JEOL 1210 electron microscope. Random electron micrographs were taken at a magnification of $10,000 \times$ and subsequently digitized (Dimage, Minolta, Japan). To measure the spatial distribution of synaptic vesicles, we used custom software routines written in Mathlab (The Mathworks, Natick MA). The location of the active zone was marked, and its minimal linear distance to the center of each individually identified vesicle was calculated. If more than one identifiable active zone was present in a terminal, each vesicle was counted only once by being included with the closest active zone. Acquisition of electron microscopy images and their analysis followed a double-blind protocol.

Behavioral assessment. The neurophysiological screen included examinations of orientation and reflexive behavior, postural and righting reflexes, and general motor coordination (Rogers et al., 1997; Ribar et al., 2000). Most measures were scored on a multipoint system. Normal responses were scored as " 0 "; negative responses denoted deficiencies, and positive scores reflected more proficient responses relative to normal or " 0 " scores. Forepaw and hindpaw strength were examined with an Ugo Basile grip-strength meter (Stoelting Company, Wood Dale, IL). Tests for ataxia and gait were evaluated by the foot-printing method (Robbins, 1985; Ribar et al., 2000). Linear strides of at least five matched footprints were used in the analyses.

Spatial working memory was examined in the eight-arm radial maze (Gainetdinov et al., 1999). Mice were food deprived $\sim 5-6 \mathrm{hr}$ before testing and maintained at $\sim 85-90 \%$ of their normal body weight throughout the study. Animals were handled twice a day for 5 consecutive days for $5 \mathrm{~min}$ and then were trained to eat the food reinforcement (Fruit Loops) before maze testing. Animals were tested daily over $24 \mathrm{~d}$ with a win-shift paradigm in which all eight arms were baited with the cereal. Individual mice were placed in a cylinder in the center of the maze for $10 \mathrm{sec}$ and then given free access to the maze for $300 \mathrm{sec}$. Only one entry into an arm was reinforced. Performance was assessed in terms of the numbers of entries before an arm was reentered (entries to repeat), the amount of food eaten and latency to eat, activity in the maze (total time in maze divided by total arm entries), and number of perseverative errors (entry into a previously entered arm).

Statistics. The data for the neurophysiological screen are expressed as normal, as delayed, as absent, or as minutes. All other results are expressed as means and SEMs. Nominal data from the neurophysiological in the two types of mice.
B

D
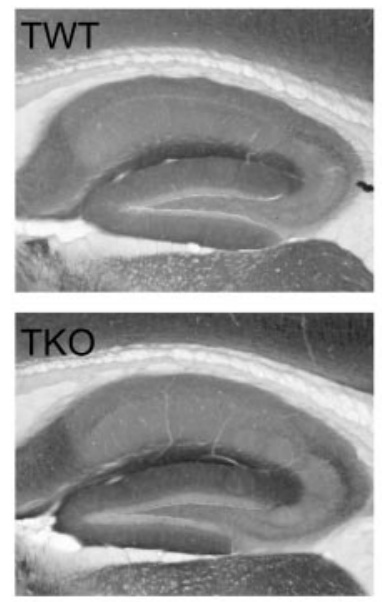

TKO

\section{Trial blocks}

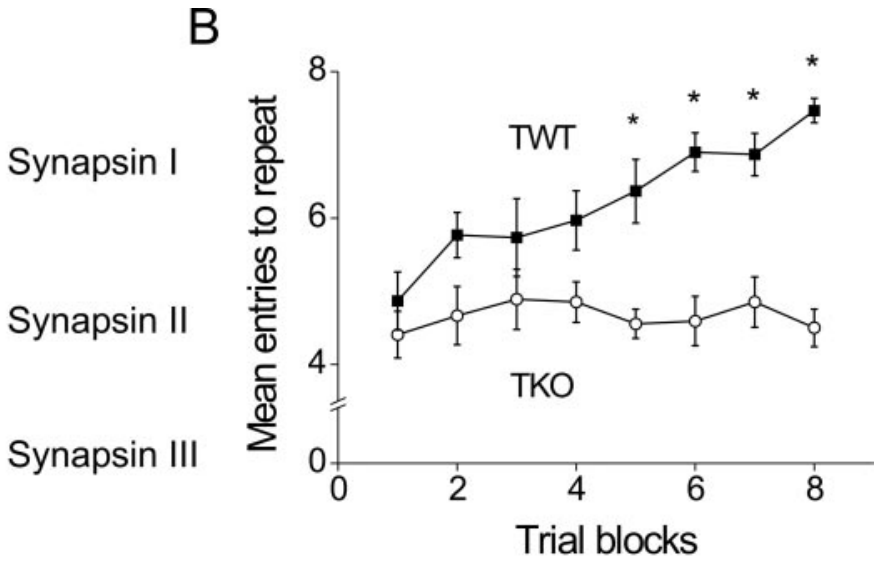

Synapsin I

Synapsin II

Synapsin III
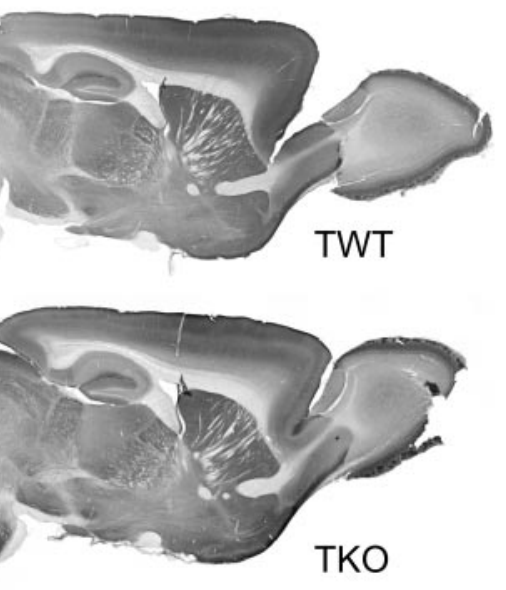

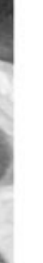

Figure 1. Brain-level effects of deleting the three synapsin genes. A, Western blot analysis of synapsins I, II, and III in wholemice ( $n=10$ and 9 , respectively) by using the win-shift paradigm in the eight-arm radial arm maze test in which all eight arms oxidase staining of sagittal sections of brains from TWT and TKO mice. D, Higher-resolution images of the hippocampal formation

assessment were analyzed by independent samples $t$ tests. The radial arm maze results were analyzed by repeated measures ANOVA (RMANOVA). To determine the time points at which TWT and TKO performance differed, tests of within-subjects contrasts with simple comparisons were used with the first block of three test trials set as the control group for each comparison. For all other comparisons, statistical significance was assessed using the Student's $t$ test, unless specified otherwise. In all cases, $p<0.05$ was considered significant.

\section{Results}

\section{Phenotype of synapsin TKO mice}

Synapsin TKO mice were generated by crossing preexisting lines of mice harboring null mutations in single synapsin genes (Chin et al., 1995; Ferreira et al., 1998; Feng et al., 2002). A line of matching wild-type mice was derived in parallel and were termed TWT mice. Although the usual complement of synapsin proteins was present in total brain lysate from TWT mice, as demonstrated by Western blots using antibodies against each synapsin gene product, the TKO mice lacked all synapsins (Fig. $1 \mathrm{~A}$ ).

Synapsin TKO mice were viable and fertile, arguing against a role for synapsins in survival; however, numerous behavioral deficits were observed in these mice (Table 1). After the initial opening of the cage, TKO mice exhibited mild and transient seizures. 
Table 1. Physiological characteristics of synapsin TWT and TKO mice

\begin{tabular}{|c|c|c|}
\hline & TWT & TKO \\
\hline \multicolumn{3}{|l|}{ Initial evaluation and general screen } \\
\hline Skin color & Normal & Normal \\
\hline Body tone & Normal & Normal \\
\hline Lacrimiation/palperbral closure & Normal & Normal \\
\hline Exopthalmus & Normal & Normal \\
\hline Convulsions/tremor & Absent & Present \\
\hline Heart rate & Normal & Normal \\
\hline Respiration rate & Normal & Normal \\
\hline Posture/tail elevation & Normal & Normal \\
\hline Barbering/hair loss & Absent & Absent \\
\hline \multicolumn{3}{|l|}{ Orientation and reflexive behavior } \\
\hline Visual orientation to object & Normal & Normal \\
\hline Visual placement & Normal & Normal \\
\hline Whisker reflex & Normal & Delayed* \\
\hline Eye reflex & Normal & Delayed* \\
\hline Pinna (ear) reflex & Normal & Delayed* \\
\hline \multicolumn{3}{|l|}{ Postural and righting reflexes } \\
\hline Postural (vertical) & Normal & Normal \\
\hline Postural (horizontal) & Normal & Abnormal* \\
\hline Contact righting & Normal & Normal \\
\hline \multicolumn{3}{|l|}{ Spinocerebellar function } \\
\hline Forepaw grasp/strength & Normal & Normal \\
\hline Hindpaw grasp/strength & Normal & Normal \\
\hline Hindpaw coordination & Normal & Abnormal* \\
\hline Wire hang (duration) & $52.0 \pm 7.5 \mathrm{sec}$ & $18.1 \pm 2.2 \sec ^{* *}$ \\
\hline \multicolumn{3}{|l|}{ Pole climbing down } \\
\hline Latency & $10.2 \pm 0.9 \mathrm{sec}$ & $1.83 \pm 1.1 \sec ^{* *}$ \\
\hline Duration & $8.4 \pm 1.9 \mathrm{sec}$ & $16.9 \pm 4.5 \mathrm{sec}$ \\
\hline \multicolumn{3}{|l|}{ Pole climbing up } \\
\hline Latency & $8.4 \pm 3.2 \mathrm{sec}$ & $4.8 \pm 1.5 \mathrm{sec}$ \\
\hline Duration & $12.1 \pm 3.4 \mathrm{sec}$ & $22.4 \pm 4.5 \mathrm{sec}$ \\
\hline \multicolumn{3}{|l|}{ Pole walking } \\
\hline Latency & $10.0 \pm 1.2 \mathrm{sec}$ & $16.1 \pm 2.3 \sec ^{*}$ \\
\hline Duration & $13.5 \pm 5.2 \mathrm{sec}$ & $31.9 \pm 4.9 \sec ^{* *}$ \\
\hline
\end{tabular}

Numerical data are expressed as means \pm SEM. The data were analyzed with an independent $t$ test. $n=10$ mice per genotype. ${ }^{*} p<0.05 ;{ }^{* *} p<0.01$

As a consequence, all behavioral tests were conducted at least 60 min after the mice were disturbed, when these seizures had subsided. Homozygous mutants exhibited delayed reflexes when their eyes, ears, or whiskers were lightly touched with the edge of a cotton swab. In each case, the TKO mice required several contacts with a cotton swab before demonstrating a reflex response. Although TWT mice demonstrated mild piloerection when handled, this characteristic was absent in the mutants. Horizontal posturing was also abnormal in the TKO mice because the animals had difficulty maintaining balance with all four paws on the floor when the cage was shaken gently in a horizontal plane. Although the grasping reflex for the front and rear paws was normal, TKO mice had a diminished ability to hang from a suspended wire. During the pole walking and climbing tests, TKO mice engaged the poles as rapidly as the TWT animals but took approximately twice as long to complete the task. The TKO mice had normal footprints, indicating an absence of ataxia. In summary, the TKO mice displayed mild abnormalities in coordination and balance, especially with their hindpaws.

To examine hippocampal function, mice were tested in a radial arm maze for spatial memory (Gainetdinov et al., 1999). Initially, the performance of both TWT and TKO mice was very poor ( $n=10$ and 9 , respectively) (Fig. $1 B$ ). After training, TWT mice improved, and very high levels of performance were achieved within 24 trials $\left(F_{(7,63)}=8.099 ; p<0.001\right)$. By comparison, the learning curve for the TKO mice was flat, suggesting that spatial learning and memory were impaired in the mutants. Tests of within-subjects contrasts demonstrated that significant differences in performance between TWT and TKO mice were evident on block trials 5 through 8 . The deficiency of TKO mice was not caused by genotypic differences in motivation because mutants showed similar latencies to eat and consumed quantities of the Fruit Loops similar to those of the TWT animals. Performance also cannot be attributed to differences in activity in the maze because these levels were comparable between genotypes. Finally, the numbers of perseverative errors were low and not significantly different between TWT and TKO mice. This latter point indicates that the TKO mice can at least remember the immediate arms that they had previously entered and could withhold responses to these arms. Together, these findings suggest that the TKO mice are deficient in spatial learning and memory.

Comparison of the brains from wild-type and synapsin TKO mice revealed no perceptible differences in gross anatomy (Fig. $1 C$ ). In particular, the structure of the hippocampus of TKO mice appeared normal (Fig. 1D). These results suggest that synapsins are not collectively required for gross development of the adult brain. Given that individual synapsin genes have been implicated in synapse formation (Ferreira and Rapoport, 2002), we also considered the number of synapses formed by TKO neurons. For this purpose, we prepared cultures of neurons from the hippocampus of TKO and TWT mice. Synapse number was determined by transfecting individual neurons with a GFP-tagged synaptophysin construct, which targets to synaptic vesicles and thereby provides a means of visualizing presynaptic terminals (Fletcher et al., 1991; Sampo et al., 2003). In neurons from both TKO and TWT mice, fluorescent puncta were observed (Fig. $2 \mathrm{~A}$, left). Counting the puncta revealed no differences in the mean number of synapses formed by the two types of neurons (Fig. $2 B$ ). This indicates that the complete absence of synapsins does not prevent synapses from forming in normal numbers.

To determine what deletion of synapsins does to the levels of synaptic proteins, we examined these proteins in homogenates prepared from TKO and TWT brains (Fig. 2C). In comparison with TWT mice, the TKO mice had selective reductions in levels of several synaptic vesicle proteins, such as synaptobrevin 2, synaptotagmin I, and synaptophysin I (Fig. 2D). Several other synaptic proteins were unaffected. For example, syntaxin I, a SNARE [soluble $\mathrm{N}$-ethylmaleimide-sensitive factor attachment protein (SNAP) receptor] protein associated with the presynaptic plasma membrane, was present at normal levels. Likewise, several proteins associated with the postsynaptic membrane, such as PSD-95 and NMDA receptor subunits NR1 and NR2B, were unaffected, as was the ubiquitous protein, $\alpha$-tubulin. The normal complement of postsynaptic membrane proteins, as well as syntaxin, is consistent with the unchanged number of synapses observed in the TKO mice (Fig. 2B). The selective reduction in synaptic vesicle proteins suggests that loss of synapsins reduced the number of synaptic vesicles, and this point is established in other experiments that are described below.

\section{Differential regulation of basal transmitter release by synapsins}

We next asked whether synaptic function was impaired in the TKO mice. For this purpose, we measured synaptic currents in hippocampal neurons in microisland cultures (Segal and Furshpan, 1990; Bekkers and Stevens, 1991). This experimental system offers several advantages over brain slices and dense cell cultures for quantifying neurotransmitter release. Most important is that the "autaptic" responses originate from the same cell, so that the 
sources of the incoming synaptic input are homogeneous and defined. As a result, evoked and spontaneous release can be recorded from the same synapses, allowing direct comparisons between these two forms of release. Finally, because synaptic transmission is unitary, the synaptic responses do not depend critically on the properties of the stimulus.

The amplitude of postsynaptic currents varied considerably between neurons, likely because of differences in the number of synapses formed by individual neurons. Because TKO and TWT neurons do not differ in their capacity to form synapses (Fig. 2A), the variability in the synaptic responses probably stems from differences in the size of individual neurons. We observed that the variance of synaptic current recordings was not statistically different (Levene's test for equal variance) between TKO and TWT neurons, suggesting that both populations were similarly affected by the factors that influence neuronal size.

In microisland cultures, autaptic responses were elicited by brief voltage pulses that evoked propagating action potentials. The resulting synaptic currents consisted of either rapidly decaying glutamatergic EPSCs, which had a time constant of decay $(\tau)$ of $6.5 \pm 0.3 \mathrm{msec}(n=$ $29)$, or slower GABAergic IPSCs $\left(\tau_{\text {fast }}=\right.$ $18.4 \pm 1.8 \mathrm{msec} ; \tau_{\text {slow }}=85 \pm 6.1 \mathrm{msec}$; $n=24$ ) (Feng et al., 2002; Thio and Yamada, 2004). Loss of synapsins affected these two types of synaptic responses in different ways.

We found that basal transmitter release was not altered in glutamatergic neurons from the synapsin TKO mice. Evoked EPSCs were very similar in waveform in TKO $(n=35)$ and TWT $(n=29)$ neurons (Fig. 3A). The peak amplitude of these EPSCs was unchanged $(p>0.85)$ in the TKO (Fig. $3 B$ ). This was also true for synaptic charge transfer, which is the time integral of the EPSCs (data not shown). Likewise, spontaneous transmitter release was very similar in TWT and TKO neurons. Spontaneous miniature EPSCs (mEPSCs) were apparent in both types of neurons (Fig. $3 C$ ), and the waveform of these mEPSCs did not differ (data not shown). The mean frequency of mEPSCs was not significantly different $(p>0.15)$ between the two types of neurons (Fig. 3D), indicating no change in the rate of spontaneous transmitter release. The mean amplitude of mEPSCs was slightly smaller in TKO neurons $(n=32)$ compared with mEPSCs recorded from TWT neurons $(n=27 ; p<0.001)$ (Fig. $3 E)$, yielding a concomitant decrease in synaptic charge transfer associated with mEPSCs in the TKO neurons. The quantal content of evoked EPSCs (Fig. 3F), calculated as the ratio of amplitudes of evoked and miniature EPSCs (del Castillo and Katz, 1954a), was not statistically different $(p>0.25)$. This indicates that a similar number of synaptic vesicles fuse with the plasma membrane in response to presynaptic action potentials in both types of neuron. Furthermore, given that TKO and TWT neurons form similar numbers of synaptic boutons (Fig. $2 \mathrm{~A}$ ), we also conclude that the mean number of fusion events per bouton is indistinguishable between TKO and TWT neurons. In summary, aside from a decrease in mEPSC amplitude, which may reflect secondary postsynaptic changes (Turrigiano and Nelson, 2004), the properties of evoked and spontaneous glutamate release from cultured hippocampal neurons were not affected by deletion of all three synapsin genes.

In contrast to the lack of influence of synapsins on glutamatergic transmission, basal inhibitory transmission was impaired substantially in the TKO neurons. Evoked IPSCs were very similar in waveform in TKO and TWT neurons (Fig. 4A); however, in TKO neurons $(n=24)$ the mean amplitude of IPSCs was reduced to $61 \%$ of the value determined for TWT neurons $(n=24 ; p<0.05)$ (Fig. $4 B)$. Spontaneous GABA release could also be observed as mIPSCs in both types of neuron (Fig. $4 C$ ). There was no difference $(p>0.4)$ in the frequency of spontaneous mIPSCs between TKO and TWT neurons (Fig. $4 D)$. Furthermore, there was also no change $(p>$ 0.85 ) in mIPSC amplitude (Fig. $4 E$ ) or amount of charge transfer associated with mIPSCs (data not shown) in TKO neurons in comparison with TWT neurons ( $n=15$ for each genotype). Finally, from the data shown in Figure 4, $B$ and $E$, the quantal content of evoked IPSCs was calculated. There was a significant $(p<0.05)$ reduction in IPSC quantal content in TKO neurons compared with TWT cells (Fig. $4 F$ ). We therefore conclude that synapsins regulate GABA release evoked by action potentials but not spontaneous GABA release. Thus, synapsins play different roles in basal transmission at different synapses: these proteins are not involved at excitatory synapses but have an important influence at inhibitory synapses. 
A

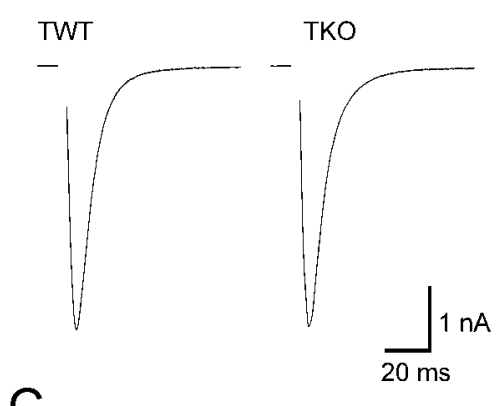

C
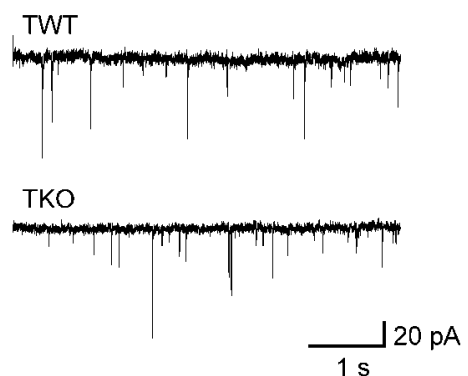

$E$

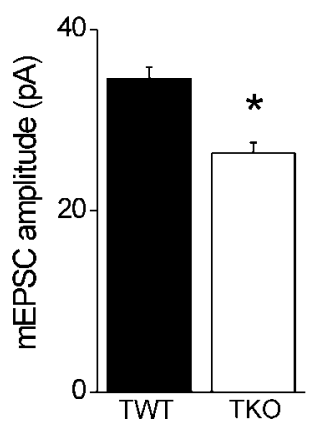

B

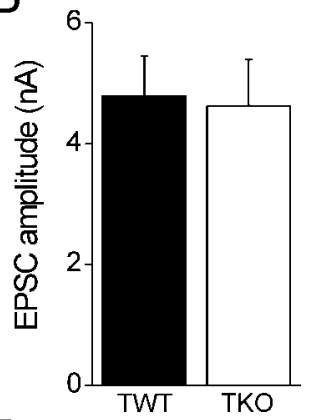

$\mathrm{D}$

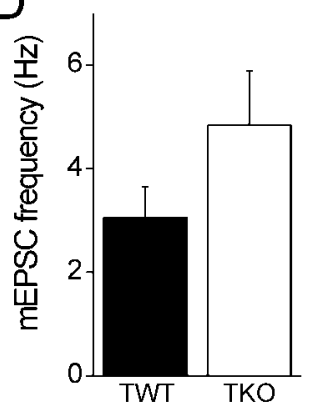

$\mathrm{F}$

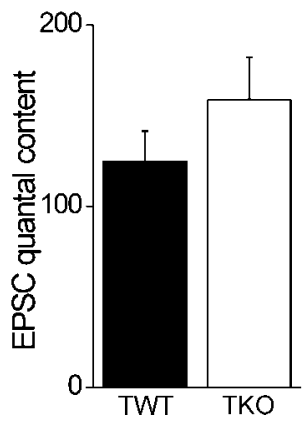

Figure 3. Basal neurotransmitter release at excitatory TWT and TKO synapses. A, Averaged evoked EPSCs from autaptic neurons from synapsin TWT and TKO mice $(n=29$ and 35 neurons, respectively). $B$, Mean amplitude of evoked EPSCS of TWT and TKO neurons. C, Representative recordings of spontaneous $m E P S C s$ in TWT and TKO neurons. D, Mean mEPSC frequency of TWT and TKO neurons ( $n=27$ and 32, respectively). E, Mean mEPSC amplitude in TWT and TKO neurons. F, Mean quantal content of EPSCs recorded from TKO and TWT neurons.

\section{Differential roles of synapsins in synaptic plasticity}

Synapsins have been implicated in various forms of synaptic plasticity. Impairment of synapsins has been reported to affect synaptic facilitation (Rosahl et al., 1995), a temporary enhancement of transmitter release caused by persistent actions of calcium within the presynaptic terminal (Zucker and Regehr, 2002). In addition, synapsins have been implicated in synaptic depression via the actions of these proteins on the reserve pool of synaptic vesicles (Greengard et al., 1993; Li et al., 1995; Pieribone et al., 1995; Hilfiker et al., 1998, 1999; Humeau et al., 2001). Therefore, we next examined whether these forms of synaptic plasticity were altered in the TKO mice.

We began by using pairs of stimuli separated by varying intervals and found that the neurons were not homogenous in their responses to such paired stimuli. At GABAergic synapses, the response to the second stimulus was always smaller than the response to the first stimulus, because of synaptic depression (see Fig. 7) (Kraushaar and Jonas, 2000). At glutamatergic synapses, the response to the second stimulus sometimes was larger than

A

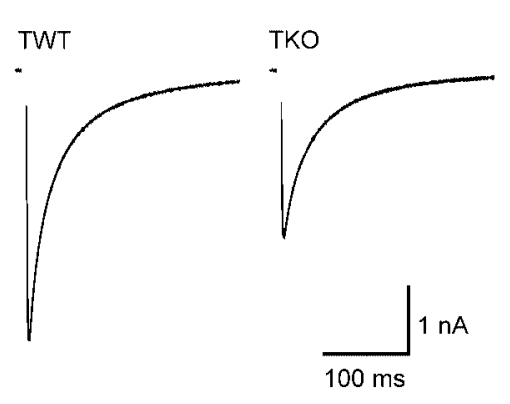

C

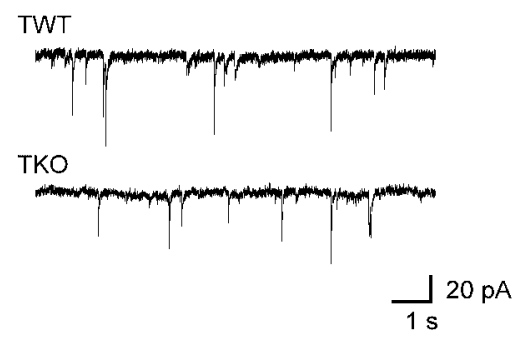

$E$

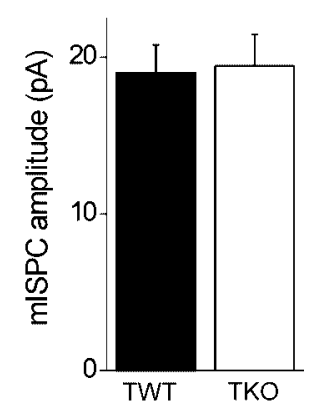

B

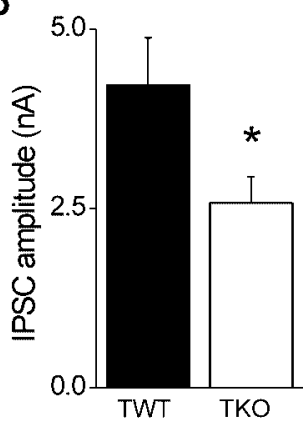

Figure 4. Basal neurotransmitter release at inhibitory synapses. A, Averaged evoked IPSCS from autaptic neurons from synapsin TWT and TKO mice ( $n=24$ neurons for each genotype). $B$, Mean amplitude of evoked IPSCs of TWT and TKO neurons. C, Representative recordings of spontaneous mIPSCs in TWT and TKO autapses. $D$, Mean mIPSC frequency in TWT and TKO neurons ( $n=15$ for each genotype). $E$, Mean mIPSC amplitude in TWT and TKO neurons. $F$, Mean quantal content of IPSCs recorded from TWT and TKO neurons.

the response to the first stimulus, because of synaptic facilitation. In other cases, synaptic depression was evident (Fig. 5A). When all excitatory responses were combined, we found no difference in the mean response of TKO $(n=14)$ and TWT $(n=20)$ neurons at any interstimulus interval examined (Fig. $5 B$ ). Because the mechanisms responsible for depression and facilitation differ (del Castillo and Katz, 1954b; Chen et al., 2004), we parsed the responses into those that showed facilitation and those that depressed. Approximately $35 \%$ of the TKO and $45 \%$ of the TWT neurons exhibited facilitation (not statistically different; $p>0.05$ in $\chi^{2}$ test). Even when separated in this way, the TKO and TWT neurons exhibited no differences in the magnitude or kinetics of synaptic facilitation or depression (Fig. 5C). The stimuli that we have used release transmitter only from the "readily releasable pool" (RRP), a small subgroup of the total recycling pool of vesicles. The RRP contains vesicles that are immediately available for release (Rosenmund and Stevens, 1996; Schikorski and Stevens, 1997, 2001), so that treatments which change the probability of transmitter release from this pool alter the response to such stim- 
A
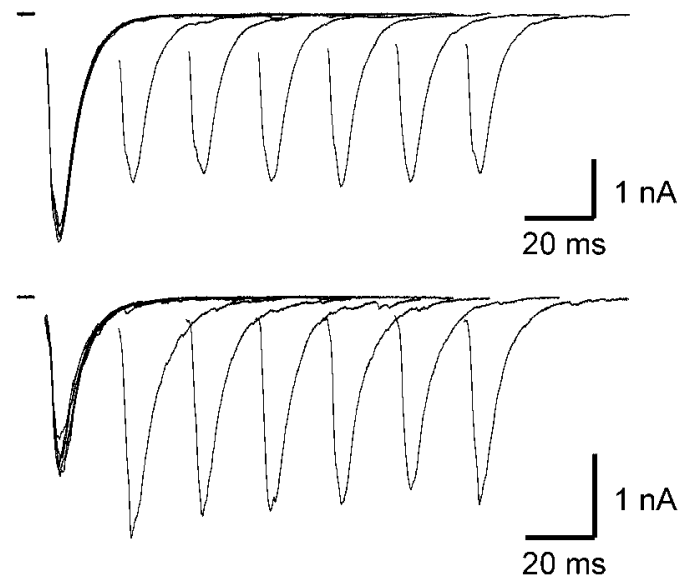

B

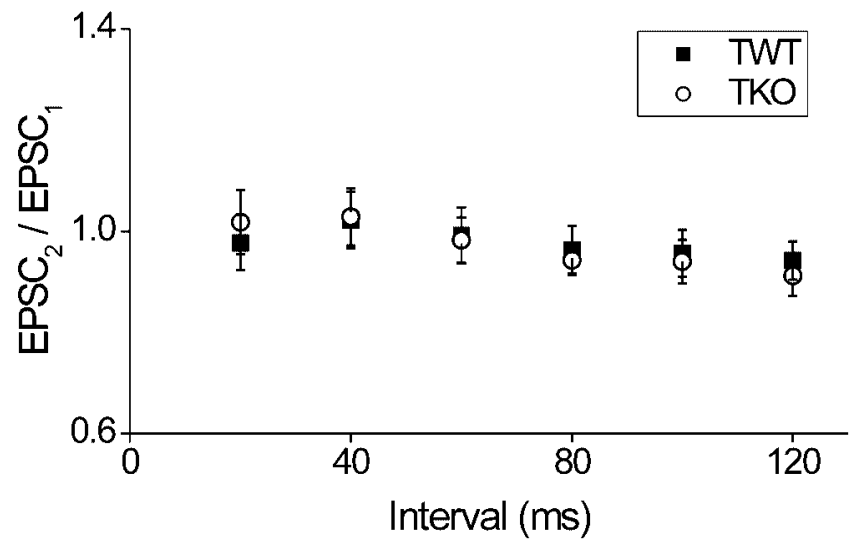

C

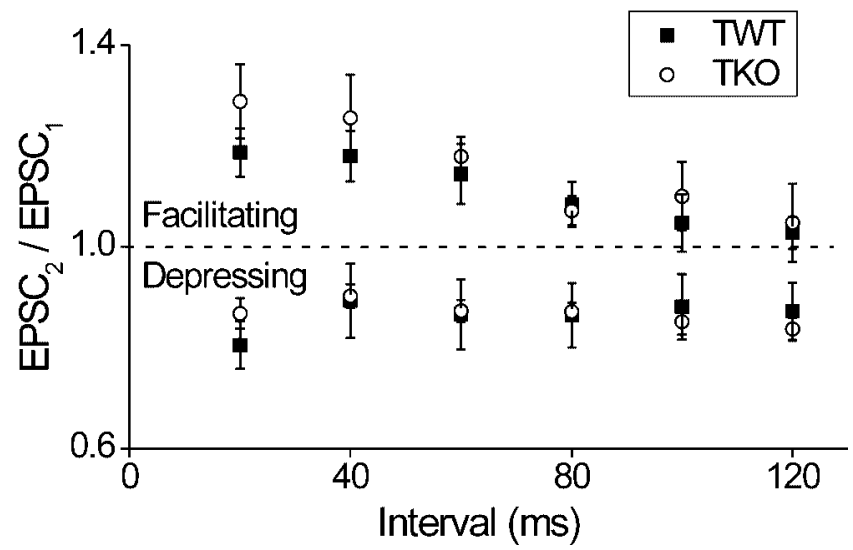

Figure 5. Short-term synaptic plasticity in TWT and TKO neurons. Pairs of stimuli were applied to TWT and TKO autaptic neurons at various interstimulus intervals, and the ratio of the amplitudes of the two responses was calculated. $A$, Sample superimposed traces of responses of two TKO neurons, one illustrating synaptic depression (top) and another illustrating synaptic facilitation (bottom). B, Mean ratio calculated for all TWT and TKO neurons ( $n=20$ and 14 , respectively). C, Mean ratios of cells parsed into those that exhibited facilitation (top) and those that depressed (bottom).

uli (Dobrunz and Stevens, 1997; Saviane et al., 2002). Thus, the fact that there was no change in the responses of TKO neurons indicates that synapsins do not change the probability that vesicles are released from the RRP. Furthermore, given that the quantal content of EPSCs is the product of the release probability and the size of the RRP (del Castillo and Katz, 1954a), our observation
A

B
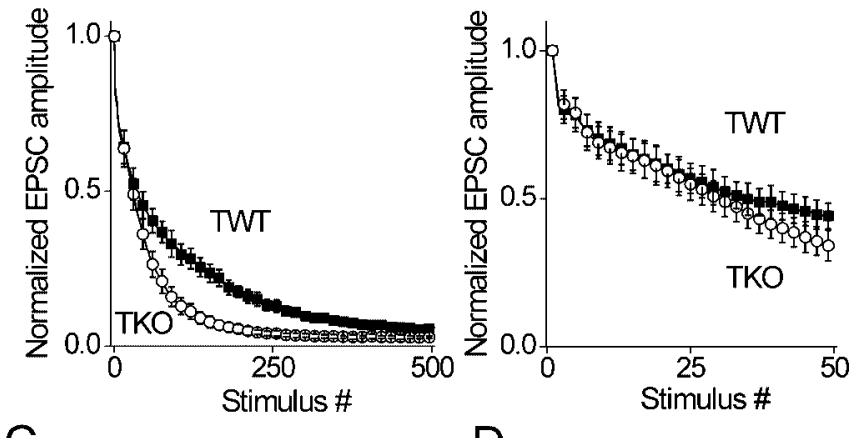

C
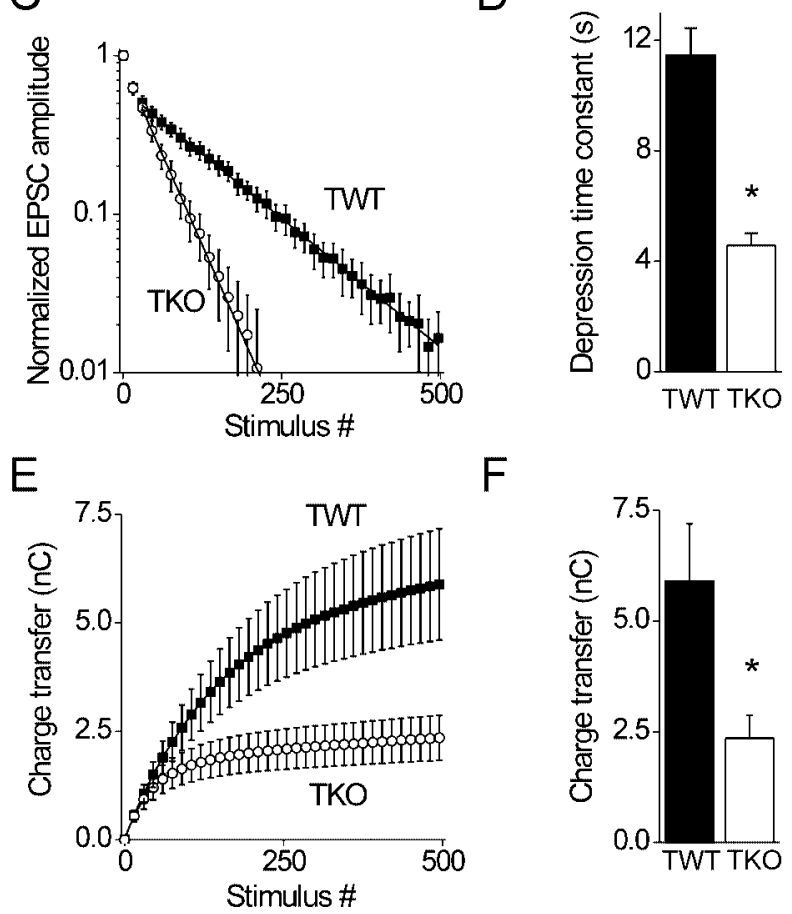

$\mathrm{F}$

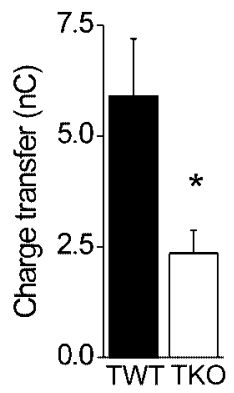

Figure 6. Characteristics of synaptic depression at excitatory synapses activated by trains of 500 stimuli applied at $10 \mathrm{~Hz}$. A, Mean EPSC amplitudes during the trains. Symbols represent EPSC amplitudes normalized to the first response in the train and every fifth response is plotted ( $n=20$ TWT neurons; $n=22$ TKO neurons). $B$, Expanded plot of the data in $A$, illustrating only responses to the first 50 stimuli in the trains. C, Semi-log scale representation of the data shown in $A$. EPSC amplitudes after the 30th response are fit by a straight line, indicating the monoexponential kinetics of synaptic depression over this period of time. D, Mean time constants for synaptic depression in TWT and TKO neurons, determined after the 30th stimulus as in C.E, Cumulative EPSC charge transfer in TWT and TKO neurons. F, Mean values for total EPSC charge transfer after 500 stimuli were applied to TWT and TKO neurons.

that quantal content is unchanged (Fig. $3 F$ ) also indicates that the size of the RRP is unchanged after loss of synapsins.

We next looked at the properties of synaptic depression by stimulating the neurons at $10 \mathrm{~Hz}$ for $50 \mathrm{sec}$, a physiologically relevant stimulus comparable with patterns of activity that have been recorded from the hippocampus in vivo (Czurko et al., 1999; Hirase et al., 1999). During such stimuli, vesicles are depleted from the RRP and can then be replenished from the RP, which represents the remainder of the pool of recycling vesicles. Under such conditions, the rate of mobilization of vesicles from the RP cannot match the rate of depletion of the RRP, leading to a net depression of EPSC amplitude (Zucker and Regehr, 2002). Such depression was evident in both TWT $(n=20)$ and TKO $(n=22)$ excitatory neurons but was substantially faster in the TKO neu- 
rons (Fig. 6A). Synaptic depression consisted of at least two phases. During the first phase, over the first 30 stimuli, the TKO neurons and TWT neurons were indistinguishable in their rates of synaptic depression (Fig. 6B). During the subsequent second phase, the rate of depression was much faster in the TKO neurons (Fig. 6A). For both TKO and TWT synapses, EPSC amplitude declined exponentially during this phase, appearing as linear functions when plotted on semilogarithmic coordinates (Fig. $6 C$ ). The time constants of these exponential declines in EPSC amplitudes were dramatically different for TKO and TWT synapses $(p<0.001)$, differing by a factor of $\sim 3$ (Fig. $6 D$ ). Thus, the kinetics of the second phase of synaptic depression depends on synapsins.

Our interpretation of these results is that the initial phase of depression, which should mainly involve depletion of vesicles from the RRP (Wesseling and Lo, 2002), is unchanged because this pool is unaffected by loss of synapsins. This is consistent with our observations on basal release and responses to paired stimuli in the TKO synapses, as described above. The large difference in the behavior of TKO and TWT neurons during the second phase, when mobilization from the RP should become more important, indicates that synapsins regulate the RP rather than the RRP.

We further examined this proposal for the dynamics of synaptic vesicle pools in TKO neurons by calculating the total amount of charge carried by EPSCs during the train of highfrequency stimuli. The postsynaptic response to a quantum is stationary during such trains (data not shown) (Zhou et al., 2000), so that depression exclusively reflects presynaptic changes (del Castillo and Katz, 1954b; Wong et al., 2003). In this case, total EPSC charge will be proportional to the number of vesicle fusion events. The loss of synapsins substantially altered the total amount of EPSC charge transfer during the trains (Fig. 6E). Although the initial rate of charge accumulation was identical in TKO and TWT synapses, later in the train the rate slowed greatly for TKO synapses. As a result, the total amount of charge transferred during the stimulus train was reduced by $>50 \%$ ( $p<$ 0.05 ) in the TKO neurons (Fig. $6 F$ ). This indicates that the cumulative number of exocytotic events during a train of activity is greatly reduced after loss of synapsins, consistent with the conclusion that synapsins are important for the RP of synaptic vesicles.

Synaptic depression was more complex in GABAergic neurons than in glutamatergic neurons. In GABAergic cells, a $10 \mathrm{~Hz}$ train of stimuli caused a very large and rapid initial depression of IPSCs, which was followed by a second, slower phase of depression (Fig. 7A). Throughout such trains, the mean amplitude of IPSCs was smaller in TKO neurons than in TWT cells (Fig. 7A); however, normalizing the amplitudes of the first IPSC in each train, to take into account the reduction in IPSC amplitude caused by loss of synapsins (Fig. 4), revealed that the kinetics of depression was identical in TKO and TWT synapses (Fig. 7B). The slow phase of IPSC depression developed exponentially for both TKO $(n=12)$ and TWT $(n=12)$ synapses (Fig. $7 C)$, with time constants that were not different between the two genotypes (Fig. 7D). Although the kinetics of IPSC depression were unchanged after loss of synapsins, IPSC charge transfer was reduced in the inhibitory TKO neurons (Fig. 7E). Both the initial accumulation of charge and the later, sustained accumulation of charge were greatly reduced for TKO synapses compared with TWT synapses. As a result, the total amount of charge transferred during the stimulus train was reduced by $>40 \%(p<0.05)$ in the TKO neurons (Fig. $7 F$ ). Thus, as was the case for glutamatergic synapses, the cumulative number of exocytotic events during a
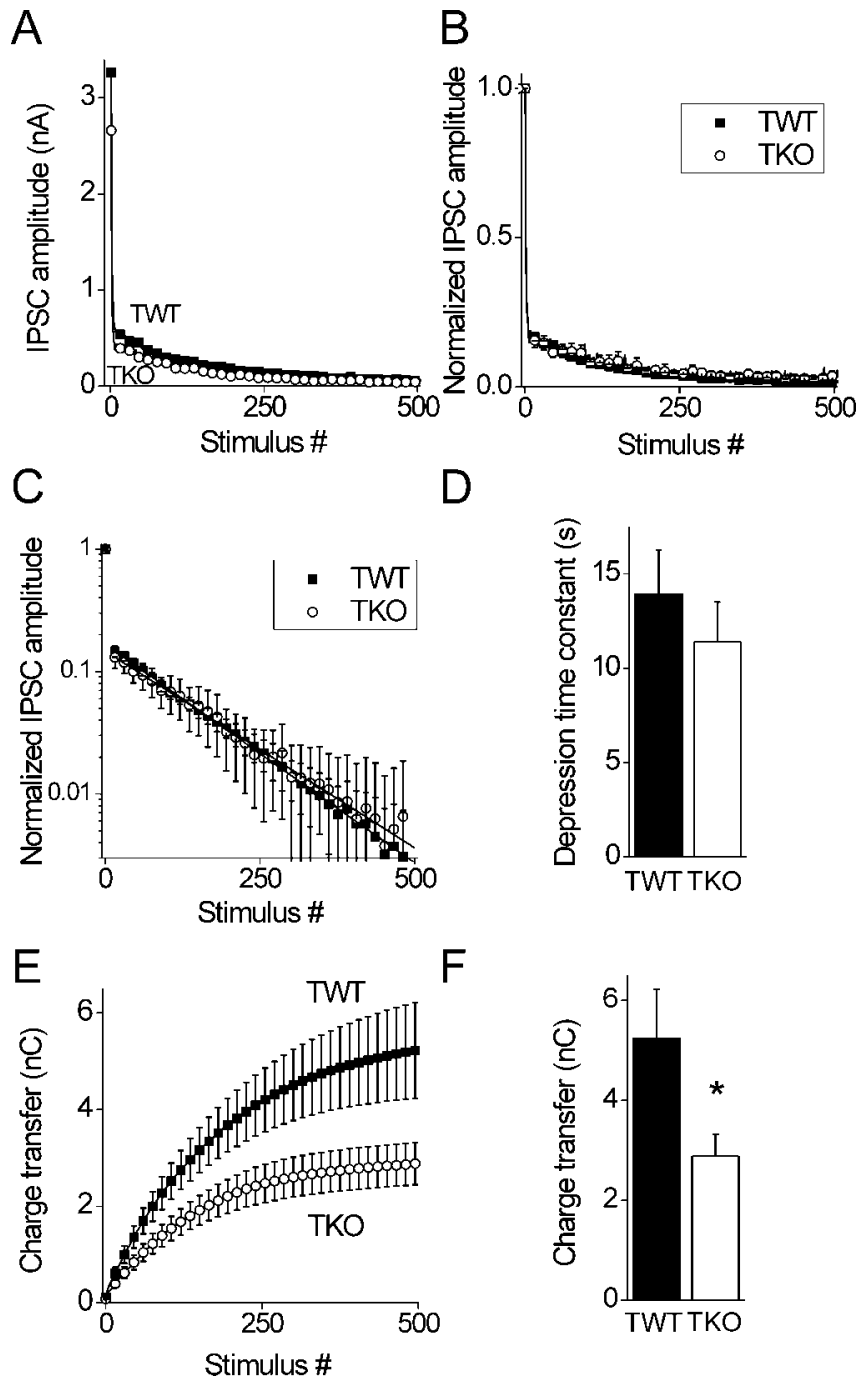

Figure 7. Characteristics of synaptic depression at inhibitory synapses activated by trains of 500 stimuli applied at $10 \mathrm{~Hz}$. A, Mean IPSC amplitudes during the train; every fifth response is plotted ( $n=12$ for each genotype). $B$, The data shown in $A$ were normalized relative to the amplitude of the first IPSC in the train. C, Semi-log scale representation of the data shown in $A$. IPSC amplitudes after the 30th response are fit by a straight line, indicating exponential kinetics. $D$, Mean time constant for IPSC depression, measured after the 30th response, in TWT and TKO neurons. $E$, Cumulative IPSC charge transfer in TWT and TKO neurons. F, Mean values for total IPSC charge transfer after 500 stimuli were applied to TWT and TKO neurons.

train of activity of GABAergic synapses was greatly reduced after loss of synapsins; however, this reduction arose from different causes at the two types of synapses. At inhibitory synapses, the reduction in the cumulative amount of release was caused by effects on the number of GABA quanta released during each stimulus, whereas at excitatory synapses, it was caused by a selective reduction in release late in the train, attributable to loss of the RP of synaptic vesicles.

\section{Synapsins differentially regulate synaptic vesicle distribution}

Our results are consistent with the notion that synapsins participate in maintaining the reserve pool of vesicles in glutamatergic neurons but play a role in basal transmission, and thus in the size of the RRP, at GABAergic synapses. To evaluate these possibilities more directly, we examined the number and spatial distribution of synaptic vesicles in TKO neurons.

We first examined the density of vesicles in living synapses by 

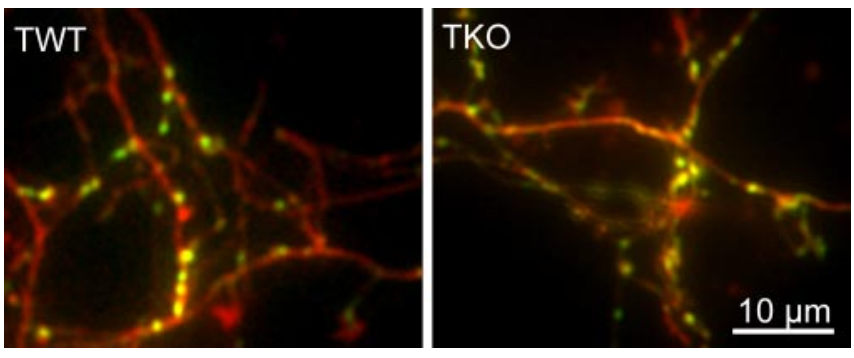

Figure 8. Synaptobrevin 2 targeting to TWT and TKO presynaptic terminals. To examine the relative enrichment of synaptic vesicles in the presynaptic terminals of cultured neurons, neurons were cotransfected with a tagged synaptic vesicle protein, GFP-synaptobrevin 2 (green), and with DsRed $_{2}$ (red). Shown are representative merged images of GFP and DsRed 2 fluorescence in axons and presynaptic terminals of transfected TWT and TKO neurons.

fluorescently tagging synaptic vesicles. Cultured neurons were transfected with the vesicle protein, synaptobrevin 2 (Baumert et al., 1989), tagged with GFP. This procedure indicates the location of synaptic vesicles (Sankaranarayanan and Ryan, 2000). Another fluorescent protein, DsRed ${ }_{2}$, was coexpressed to visualize the cytoplasmic volume of the neuron. In both TKO and TWT cells, these procedures revealed green synaptic boutons associated with red axons (Fig. 8).

To quantify the amount of synaptobrevin in the terminals, we calculated a "targeting factor" (Gitler et al., 2004). This was calculated as the ratio of the intensity of GFP-synaptobrevin fluorescence in the terminals compared with that of the axon, corrected for the volume of the terminals and axons via the intensity

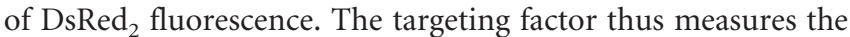
relative density of synaptobrevin in the terminals, which should be proportional to the number of synaptic vesicles. The targeting factor of synaptobrevin in TKO neurons $(n=8 ; 1.21 \pm 0.15)$ was significantly lower $(p<0.001)$ than that measured in TWT neurons $(n=15 ; 3.58 \pm 0.54)$. Because the mean expression level of the GFP--synaptobrevin was similar in the TWT and TKO neurons, as determined by measuring the fluorescence of nonsynaptic axonal segments $(p>0.5)$, the differences observed between synaptobrevin targeting in TKO and TWT neurons cannot be attributed to possible effects of level of expression on synaptobrevin targeting. Thus, the loss of synapsins apparently caused a reduction in the relative number of vesicles in the TKO terminals.

We next used electron microscopy to examine directly the number and spatial distribution of vesicles within presynaptic terminals. This method also allowed us to discriminate between glutamatergic and GABAergic synapses, with "asymmetrical" glutamatergic synapses found on dendritic spines and shafts and "symmetrical" GABAergic synapses found predominantly on somata and, occasionally, on thick dendrites (Bartlett and Banker, 1984; Megias et al., 2001).

Glutamatergic presynaptic terminals from TKO and TWT neurons were fairly similar in appearance (Fig. 9A), although the TKO terminals appeared to have fewer synaptic vesicles. At increasing distances away from the active zone, there were fewer vesicles in TKO terminals than in TWT terminals (Fig. 9B), as was quantified by measuring the spatial distribution of synaptic vesicles (Hess et al., 1993; Pieribone et al., 1995; Hilfiker et al., 1998). This difference between TKO and TWT terminals was seen most readily by calculating a ratio between the number of vesicles in each spatial compartment of the two types of terminals (Fig. 9C). The calculated relative number of vesicles in the TKO terminals was unchanged within $50 \mathrm{~nm}$ of the active zone but decreased exponentially over greater distances, reaching a level of $\sim 0.3$ that of the TWT terminals at a distance $500 \mathrm{~nm}$ away from the active zone (Fig. 9C). The vesicles within $50 \mathrm{~nm}$ of the active zone are primarily docked vesicles, which are thought to represent the RRP (Schikorski and Stevens, 1997, 2001). We quantified the number of docked vesicles by counting only vesicles that touched the plasma membrane (Bommert et al., 1993) and found that there was no difference in the number of docked vesicles in TWT $(n=47)$ and TKO terminals $(n=66 ; p>0.3)$ (Fig. 9D). To determine the total number of synaptic vesicles present, we integrated the distributions shown in Figure $9 B$ over the entire range of distances analyzed. Glutamatergic TKO terminals had a much smaller number of vesicles than did their TWT counterparts (Fig. $9 E$ ). The $48 \%$ reduction in the number of vesicles is very similar to the degree of reduction in the cumulative number of quanta released from TKO terminals during trains of activity (Fig. $6 F$ ). It is also consistent with the reduction in synaptic vesicle number inferred from our measurements of GFP-synaptobrevin 2 (Fig. 8 ), which were made mainly from excitatory synapses ( $\sim 75 \%$ of the cultured neurons are glutamatergic, based on electrophysiological measurements of postsynaptic currents). Thus, loss of synapsins causes a preferential loss of synaptic vesicles that are away from the active zone, a population of vesicles that has been attributed to the RP (Pieribone et al., 1995).

The structural consequences of deleting the synapsin genes were quite different for GABAergic synapses (Fig. 9F). Examination of the spatial distribution of synaptic vesicles within inhibitory terminals (Fig. 9G) revealed a roughly uniform reduction in vesicle number throughout the terminal (Fig. 9H). This is in stark contrast to the relationship observed in excitatory terminals (Fig. $9 C)$. In particular, the number of docked vesicles in the TKO inhibitory terminals $(n=57)$ was significantly smaller in comparison with that in the TWT terminals (Fig. 9I) $(n=55 ; p<$ $0.05)$. This also differs from the case of the excitatory synapses but is consistent with the smaller amplitude and quantal content of inhibitory basal neurotransmission in TKO neurons (Fig. 4B,F). The total number of synaptic vesicles in the TKO inhibitory terminals was reduced by $34 \%$ in comparison with their number in TWT inhibitory terminals (Fig. 9J). This is a smaller reduction than that observed in glutamatergic TKO terminals (Fig. 9E) but is consistent with the degree of reduction in the cumulative number of quanta released from inhibitory TKO terminals during trains of activity (Fig. $7 F$ ). Thus, loss of synapsins has different effects on the structure of excitatory and inhibitory synapses, and these structural changes can account for the changes in neurotransmitter release caused by deletion of the synapsin genes.

\section{Discussion}

We have used a molecular genetic approach to examine the functions of synapsins in the mammalian brain and have found that synapsins are involved in transmission at both glutamatergic and GABAergic synapses. Previous genetic studies of mammalian synapsins have been confounded by the presence of multiple synapsin genes that might compensate for each other (Rosahl et al., 1993, 1995; Li et al., 1995; Ryan et al., 1996; Feng et al., 2002). We have avoided such issues by generating mice lacking all synapsins. Such mice are viable and fertile, indicating that synapsins are not essential for basic brain function. Lack of synapsins does lead to numerous behavioral alterations, such as delayed reflexes and deficits in spatial learning or memory (Silva et al., 1996). Additionally, the synapsin TKO mice suffer from epileptic-like seizures, as do some of the single knock-outs, consistent with an imbalance in excitability of the nervous system (Puranam and McNamara, 1999). This parallels a recent report linking one type 
A

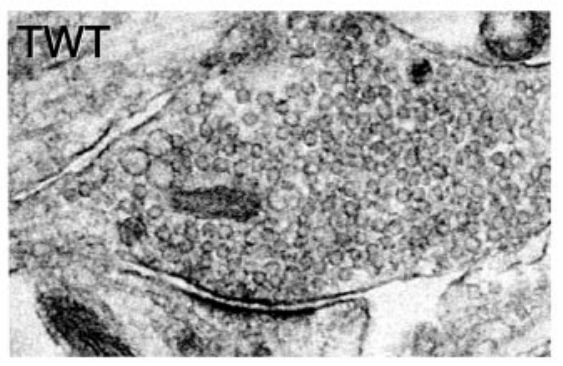

Excitatory

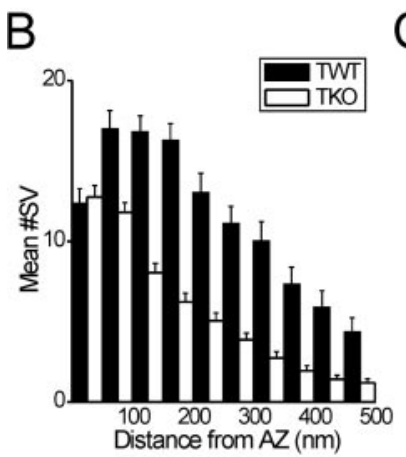

C
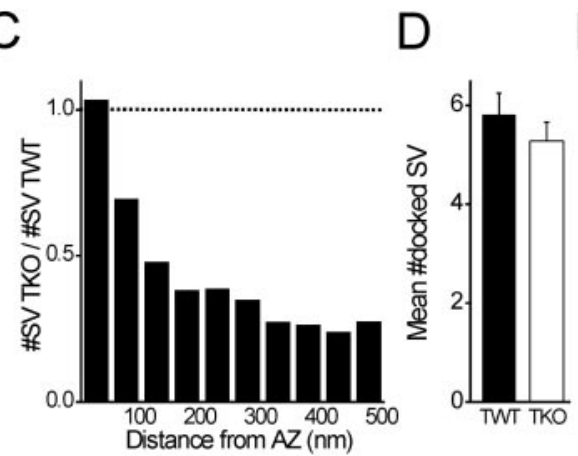

$\mathrm{F}$

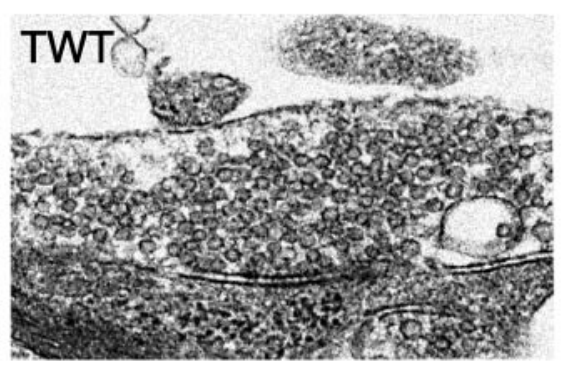

Inhibitory
G

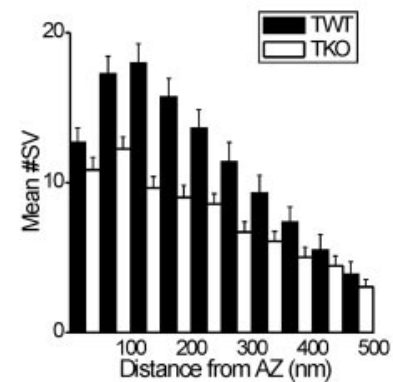

$\mathrm{H}$

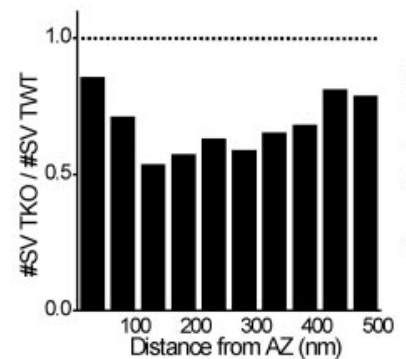

I
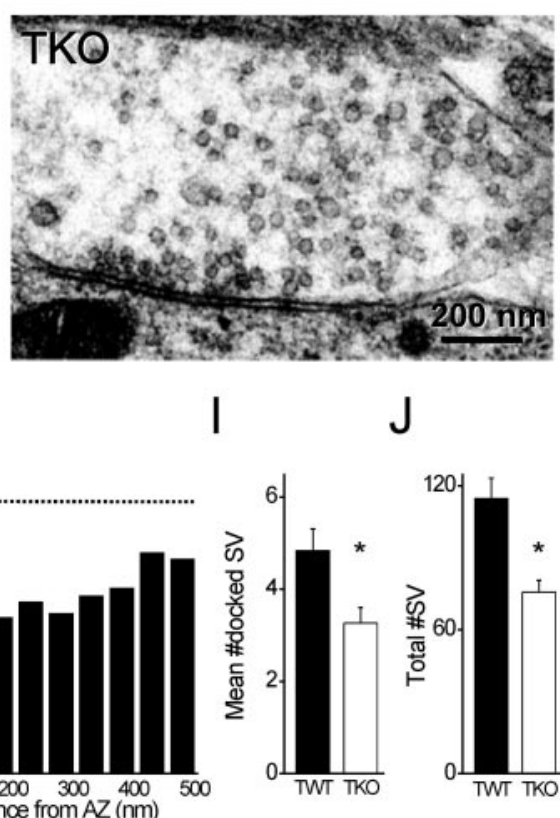

Figure 9. Spatial distribution of synaptic vesicles (SVs) in presynaptic terminals. $A$, Representative electron micrographs of excitatory terminals of TWT and TKO neurons. B, Mean number of synaptic vesicles located within 50-nm-wide concentric compartments centered at the active zone of TWT and TKO neurons ( $n=47$ and 66 terminals, respectively). C, Ratio of the number of vesicles in the various compartments, calculated from the data shown in $B$ by dividing TKO values by the TWT values. Dashed line marks equality between TWT and TKO data. D, Mean number of morphologically docked vesicles in TWT and TKO terminals. $E$, Mean total number of vesicles up to $500 \mathrm{~nm}$ from the active zone in TWT and TKO terminals. F-J, Comparable analysis of inhibitory TWT and TKO terminals ( $n=55$ and 57 terminals, respectively).

of familial epilepsy to a mutation in the human synapsin I gene (Garcia et al., 2004).

\section{Synapsins are not essential for synaptic transmission}

Our main findings are that synapsins regulate synaptic transmission but are not essential for synaptic function and that the roles
$\mathrm{E}$
$\mathrm{J}$

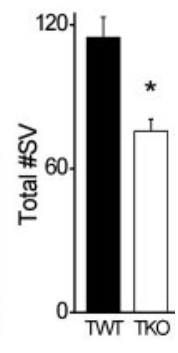

of these proteins are synapse specific. We found that synapsins have more effect on basal transmission at inhibitory synapses and more effect on depression at excitatory synapses. In some experimental systems, interference with synapsins appears to have little effect on basal transmission but does affect synaptic plasticity (Li et al., 1995; Pieribone et al., 1995; Rosahl et al., 1995; Ryan et al., 1996; Humeau et al., 2001; Feng et al., 2002). At the squid giant synapse, acute interference with synapsins disrupts synaptic plasticity but additionally inhibits basal synaptic transmission (Llinas et al., 1985, 1991; Hilfiker et al., 1998). It is possible that the synapsespecific differences in the roles of synapsins that we found could underlie some of the differences reported for the functions of synapsins at other synapses. Alternatively, compensation of synapsin function by other genes, which is not an issue in the acute experiments in squid, could obscure the effects of synapsins on basal release in other systems.

\section{Differential regulation of vesicle} trafficking by synapsins

Several of our results indicate that synapsins control the number of synaptic vesicles in both excitatory and inhibitory terminals. First, in TKO brains the quantity of synaptic vesicle proteins was reduced, whereas nonvesicular synaptic proteins were unchanged (Fig. 2D). This was also reported for mice in which synapsin I and II genes were knocked out (Rosahl et al., 1995). Second, synaptobrevin 2 targeting was reduced in TKO presynaptic terminals (Fig. 8). Finally, electron microscopy indicated that the numbers of glutamatergic (Fig. 9E) and GABAergic (Fig. 9J) vesicles in the terminals were lower in the synapsin TKO synapses. Thus, synapsins regulate synaptic vesicle trafficking in both excitatory and inhibitory terminals.

Although vesicle number was reduced in both types of terminals, deletion of synapsins affected the RP and RRP differently in each. Several lines of evidence indicate that the RRP is intact at excitatory synapses of synapsin TKO mice. First, the quantal content of EPSCs, which is the product of vesicular release probability and the size of the RRP, was unchanged in TKO synapses (Fig. 3G). Second, responses to paired stimuli were similar in TKO and TWT neurons, suggesting no effect on release probability (Dobrunz and Stevens, 1997). The conjunction of these two observations means that the RRP is unchanged after loss of synapsins. Also consistent with a lack of effect of synapsins on RRP size is our observation that responses to the first 30 stimuli in a train are equal in TKO and TWT synapses (Fig. 6B) (Murthy and 
Stevens, 1999; Wesseling and Lo, 2002). Finally, the number of docked vesicles was virtually identical in TWT and TKO neurons (Fig. 9D), although the total number of vesicles was vastly different (Fig. 9E). Therefore, synapsins do not play a significant role in determining the size of the RRP at excitatory synapses.

Although synapsins did not affect the size of the RRP, synaptic vesicles away from the active zone were depleted in TKO excitatory synapses (Fig. 9C). This population of vesicles has previously been attributed to the RP (Pieribone et al., 1995). Furthermore, loss of synapsins accelerated synaptic depression, indicating an impaired RP. Similar results have been observed after several other experimental perturbations of synapsin function (Pieribone et al., 1995; Rosahl et al., 1995; Hilfiker et al., 1998; Humeau et al., 2001). Thus, synapsins determine the size of the RP of glutamatergic vesicles but do not influence the size of the RRP. Our results therefore indicate that synapsins, and consequently the size of the reserve pool, are critical for defining synaptic excitatory transmission at moderate rates of synaptic activity (Sara et al., 2002). Furthermore, our results are consistent with the conventional view that the RRP is segregated to a spatial compartment near the active zone (Schikorski and Stevens, 1997, 2001; Millar et al., 2002; Satzler et al., 2002), contrary to a recent report (Rizzoli and Betz, 2004).

At inhibitory terminals, the amount of GABA released by single stimuli was decreased in the TKOs, whereas the kinetics of synaptic depression was unaffected. These changes in GABA release are consistent with the overall loss of synaptic vesicles in these terminals (Fig. 9H), with the reduction in responses to single stimuli attributable to loss of docked synaptic vesicles within the RRP (Fig. 9I). Such a reduction in the size of the RRP might be expected to hasten the rate of depletion of this pool during depression (Elmqvist and Quastel, 1965; Betz, 1970; Kusano and Landau, 1975); however, the initial, fast component of depression of GABA release is reported to be caused by a useindependent mechanism (Hefft et al., 2002) (but see Jensen et al., 1999) rather than depletion of the RRP. Thus, our observation that loss of synapsins does not affect the magnitude or rate of depression is consistent with the known properties of the RRP of GABAergic vesicles.

Comparison of our results with those obtained from mice deficient in one or two synapsin genes provides a consistent picture of the function of synapsins. Although there have been no measurements of quantal content at excitatory synapses where synapsin I or synapsin II are knocked out, our finding that quantal content at these synapses was not affected by deleting all three synapsin genes (Fig. $3 G$ ) is consistent with a report that knockout of synapsin III does not affect quantal content (Feng et al., 2002). The accelerated rate of depression of EPSCs at TKO synapses (Fig. 6C,D) is consistent with reports that deletion of synapsin II enhances depression (Rosahl et al., 1995). In contrast, disruption of the synapsin I gene does not affect the kinetics of depression at excitatory synapses (Rosahl et al., 1995), whereas deletion of synapsin III slows the rate of depression (Feng et al., 2002). Thus, the actions of synapsins on the RP at mammalian glutamatergic synapses apparently are mediated primarily by synapsin II.

GABAergic transmission has been examined in synapsin I (Terada et al., 1999) and synapsin III (Feng et al., 2002) null mice. In both cases, inhibitory synaptic transmission was reduced, suggesting that synapsin I and synapsin III each contribute to the RRP at inhibitory synapses; however, this deduction conflicts with the observation of Terada et al. (1999) that the number of synaptic vesicles in unstimulated inhibitory terminals was unaffected by deletion of synapsin I.

The RRP and the RP also appear to interact differently at excitatory and inhibitory synapses. At excitatory synapses, the loss of synapsins affects the number of vesicles in the RP but not the RRP, indicating that the size of the RRP is not determined by the total number of vesicles in the terminal, as would happen under a mass-action model (Li and Schwarz, 1999). Instead, the supply of vesicles to the RRP is uncoupled from the size of the RP and controlled by local events at the active zone, such as docking reactions (Robinson and Martin, 1998). Uncoupling between these pools also implies that detachment of vesicles from the RRP pool and their incorporation into the RP is rare; otherwise, these two pools would equilibrate (but see Murthy and Stevens, 1999). At inhibitory synapses, the loss of synapsins decreases the RP and RRP in parallel, suggesting that a mass-action mechanism may operate at these terminals. The molecular underpinnings of this difference between excitatory and inhibitory terminals are unclear but could be caused by expression of different synapsin isoforms in the two terminals (Südhof et al., 1989). Alternatively, given that release of GABA appears to require SNAP-23, rather than SNAP-25 (Verderio et al., 2004), and that SNAP-23 enables depriming of vesicles more readily than SNAP-25 (Sorensen et al., 2003), impairment of the RP in inhibitory terminals could result in a reduction in the size of the RRP.

In summary, synapsins are important regulators of synaptic vesicle trafficking in presynaptic terminals. At excitatory synapses, they determine the number of vesicles in the RP and at inhibitory synapses they determine the number of vesicles in both the RRP and the RP. These findings reveal that the molecular mechanisms responsible for distributing synaptic vesicles to the RRP and RP must be different in these two types of terminals. These differences presumably arise from differences in the behavior of synapsin isoforms, and/or their numerous binding partners, at excitatory and inhibitory terminals, raising important questions for future investigations of synapsin action in presynaptic terminals.

\section{References}

Bartlett W, Banker G (1984) An electron microscopic study of the development of axons and dendrites by hippocampal neurons in culture. II. Synaptic relationships. J Neurosci 4:1954-1965.

Baumert M, Maycox PR, Navone F, De Camilli P, Jahn R (1989) Synaptobrevin: an integral membrane protein of 18,000 daltons present in small synaptic vesicles of rat brain. EMBO J 8:379-384.

Bekkers J, Stevens C (1991) Excitatory and inhibitory autaptic currents in isolated hippocampal neurons maintained in cell culture. Proc Natl Acad Sci USA 88:7834-7838.

Betz WJ (1970) Depression of transmitter release at the neuromuscular junction of the frog. J Physiol (Lond) 206:629-644.

Bloom O, Evergren E, Tomilin N, Kjaerulff O, Low P, Brodin L, Pieribone VA, Greengard P, Shupliakov O (2003) Colocalization of synapsin and actin during synaptic vesicle recycling. J Cell Biol 161:737-747.

Bommert K, Charlton MP, DeBello WM, Chin GJ, Betz H, Augustine GJ (1993) Inhibition of neurotransmitter release by C2-domain peptides implicates synaptotagmin in exocytosis. Nature 363:163-165.

Chen G, Harata NC, Tsien RW (2004) Paired-pulse depression of unitary quantal amplitude at single hippocampal synapses. Proc Natl Acad Sci USA 101:1063-1068.

Chin LS, Li L, Ferreira A, Kosik KS, Greengard P (1995) Impairment of axonal development and of synaptogenesis in hippocampal neurons of synapsin I-deficient mice. Proc Natl Acad Sci USA 92:9230-9234.

Czurko A, Hirase H, Csicsvari J, Buzsaki G (1999) Sustained activation of hippocampal pyramidal cells by "space clamping" in a running wheel. Eur J Neurosci 11:344-352.

del Castillo J, Katz B (1954a) Quantal components of the end-plate potential. J Physiol (Lond) 124:560-573. 
del Castillo J, Katz B (1954b) Statistical factors involved in neuromuscular facilitation and depression. J Physiol (Lond) 124:574-585.

Dobrunz LE, Stevens CF (1997) Heterogeneity of release probability, facilitation, and depletion at central synapses. Neuron 18:995-1008.

Elmqvist D, Quastel DM (1965) A quantitative study of end-plate potentials in isolated human muscle. J Physiol (Lond) 178:505-529.

Feng J, Chi P, Blanpied TA, Xu Y, Magarinos AM, Ferreira A, Takahashi RH, Kao HT, McEwen BS, Ryan TA, Augustine GJ, Greengard P (2002) Regulation of neurotransmitter release by synapsin III. J Neurosci 22:4372-4380.

Ferreira A, Rapoport M (2002) The synapsins: beyond the regulation of neurotransmitter release. Cell Mol Life Sci 59:589-595.

Ferreira A, Chin LS, Li L, Lanier LM, Kosik KS, Greengard P (1998) Distinct roles of synapsin I and synapsin II during neuronal development. Mol Med 4:22-28.

Fletcher TL, Cameron P, De Camilli P, Banker G (1991) The distribution of synapsin I and synaptophysin in hippocampal neurons developing in culture. J Neurosci 11:1617-1626.

Gainetdinov RR, Wetsel WC, Jones SR, Levin ED, Jaber M, Caron MG (1999) Role of serotonin in the paradoxical calming effect of psychostimulants on hyperactivity. Science 283:397-401.

Garcia CC, Blair HJ, Seager M, Coulthard A, Tennant S, Buddles M, Curtis A, Goodship JA (2004) Identification of a mutation in synapsin I, a synaptic vesicle protein, in a family with epilepsy. J Med Genet 41:183-186.

Gitler D, Xu Y, Kao H-T, Lin D, Lim S, Feng J, Greengard P, Augustine GJ (2004) Molecular determinants of synapsin targeting to presynaptic terminals. J Neurosci 24:3711-3720.

Godenschwege TA, Reisch D, Diegelmann S, Eberle K, Funk N, Heisenberg M, Hoppe V, Hoppe J, Klagges BR, Martin JR, Nikitina EA, Putz G, Reifegerste R, Reisch N, Rister J, Schaupp M, Scholz H, Schwarzel M, Werner U, Zars TD, et al. (2004) Flies lacking all synapsins are unexpectedly healthy but are impaired in complex behaviour. Eur J Neurosci 20:611-622.

Greengard P, Valtorta F, Czernik AJ, Benfenati F (1993) Synaptic vesicle phosphoproteins and regulation of synaptic function. Science 259:780-785.

Hefft S, Kraushaar U, Geiger JRP, Jonas P (2002) Presynaptic short-term depression is maintained during regulation of transmitter release at a GABAergic synapse in rat hippocampus. J Physiol (Lond) 539:201-208.

Hess SD, Doroshenko PA, Augustine GJ (1993) A functional role for GTPbinding proteins in synaptic vesicle cycling. Science 259:1169-1172.

Hilfiker S, Schweizer FE, Kao HT, Czernik AJ, Greengard P, Augustine GJ (1998) Two sites of action for synapsin domain $\mathrm{E}$ in regulating neurotransmitter release. Nat Neurosci 1:29-35.

Hilfiker S, Pieribone VA, Czernik AJ, Kao HT, Augustine GJ, Greengard P (1999) Synapsins as regulators of neurotransmitter release. Philos Trans R Soc Lond B Biol Sci 354:269-279.

Hirase H, Czurko A, Csicsvari J, Buzsaki G (1999) Firing rate and thetaphase coding by hippocampal pyramidal neurons during "space clamping". Eur J Neurosci 11:4373-4380.

Humeau Y, Doussau F, Vitiello F, Greengard P, Benfenati F, Poulain B (2001) Synapsin controls both reserve and releasable synaptic vesicle pools during neuronal activity and short-term plasticity in Aplysia. J Neurosci 21:4195-4206.

Jensen K, Lambert JDC, Jensen MS (1999) Activity-dependent depression of GABAergic IPSCs in cultured hippocampal neurons. J Neurophysiol $82: 42-49$.

Kao HT, Porton B, Hilfiker S, Stefani G, Pieribone VA, DeSalle R, Greengard P (1999) Molecular evolution of the synapsin gene family. J Exp Zool 285:360-377.

Kraushaar U, Jonas P (2000) Efficacy and stability of quantal GABA release at a hippocampal interneuron-principal neuron synapse. J Neurosci 20:5594-5607.

Kusano K, Landau EM (1975) Depression and recovery of transmission at the squid giant synapse. J Physiol (Lond) 245:13-22.

Li J, Schwarz TL (1999) Genetic evidence for an equilibrium between docked and undocked vesicles. Philos Trans R Soc Lond B Biol Sci 354:299-306.

Li L, Chin LS, Shupliakov O, Brodin L, Sihra TS, Hvalby O, Jensen V, Zheng D, McNamara JO, Greengard P, Andersen P (1995) Impairment of synaptic vesicle clustering and of synaptic transmission, and increased seizure propensity, in synapsin I-deficient mice. Proc Natl Acad Sci USA 92:9235-9239.

Llinas R, McGuinness TL, Leonard CS, Sugimori M, Greengard P (1985) Intraterminal injection of synapsin I or calcium/calmodulin-dependent protein kinase II alters neurotransmitter release at the squid giant synapse. Proc Natl Acad Sci USA 82:3035-3039.

Llinas R, Gruner JA, Sugimori M, McGuinness TL, Greengard P (1991) Regulation by synapsin I and $\mathrm{Ca}(2+)$-calmodulin-dependent protein kinase II of the transmitter release in squid giant synapse. J Physiol (Lond) 436:257-282.

Megias M, Emri Z, Freund TF, Gulyas AI (2001) Total number and distribution of inhibitory and excitatory synapses on hippocampal CA1 pyramidal cells. Neuroscience 102:527-540.

Millar AG, Bradacs H, Charlton MP, Atwood HL (2002) Inverse relationship between release probability and readily releasable vesicles in depressing and facilitating synapses. J Neurosci 22:9661-9667.

Murthy VN, Stevens CF (1999) Reversal of synaptic vesicle docking at central synapses. Nat Neurosci 2:503-507.

Nishiki T, Augustine GJ (2004) Synaptotagmin I synchronizes transmitter release in mouse hippocampal neurons. J Neurosci 24:6127-6132.

Pieribone VA, Shupliakov O, Brodin L, Hilfiker-Rothenfluh S, Czernik AJ, Greengard P (1995) Distinct pools of synaptic vesicles in neurotransmitter release. Nature 375:493-497.

Porton B, Kao HT, Greengard P (1999) Characterization of transcripts from the synapsin III gene locus. J Neurochem 73:2266-2271.

Puranam RS, McNamara JO (1999) Seizure disorders in mutant mice: relevance to human epilepsies. Curr Opin Neurobiol 9:281-287.

Ribar TJ, Rodriguiz RM, Khiroug L, Wetsel WC, Augustine GJ, Means AR (2000) Cerebellar defects in $\mathrm{Ca}^{2+} /$ calmodulin kinase IV-deficient mice. J Neurosci 20:RC107(1-5).

Rizzoli SO, Betz WJ (2004) The structural organization of the readily releasable pool of synaptic vesicles. Science 303:2037-2039.

Robbins LM (1985) Footprints: collection, analyses, and interpretation. Springfield, IL: Thomas.

Robinson LJ, Martin TF (1998) Docking and fusion in neurosecretion. Curr Opin Cell Biol 10:483-492.

Rogers DC, Fisher EM, Brown SD, Peters J, Hunter AJ, Martin JE (1997) Behavioral and functional analysis of mouse phenotype: SHIRPA, a proposed protocol for comprehensive phenotype assessment. Mamm Genome 8:711-713.

Rosahl TW, Geppert M, Spillane D, Herz J, Hammer RE, Malenka RC, Südhof TC (1993) Short-term synaptic plasticity is altered in mice lacking synapsin I. Cell 75:661-670.

Rosahl TW, Spillane D, Missler M, Herz J, Selig DK, Wolff JR, Hammer RE, Malenka RC, Südhof TC (1995) Essential functions of synapsins I and II in synaptic vesicle regulation. Nature 375:488-493.

Rosenmund C, Stevens CF (1996) Definition of the readily releasable pool of vesicles at hippocampal synapses. Neuron 16:1197-1207.

Ryan TA, Li L, Chin LS, Greengard P, Smith SJ (1996) Synaptic vesicle recycling in synapsin I knock-out mice. J Cell Biol 134:1219-1227.

Sampo B, Kaech S, Kunz S, Banker G (2003) Two distinct mechanisms target membrane proteins to the axonal surface. Neuron 37:611-624.

Sankaranarayanan S, Ryan TA (2000) Real-time measurements of vesicleSNARE recycling in synapses of the central nervous system. Nat Cell Biol 2:197-204.

Sara Y, Mozhayeva MG, Liu XR, Kavalali ET (2002) Fast vesicle recycling supports neurotransmission during sustained stimulation at hippocampal synapses. J Neurosci 22:1608-1617.

Satzler K, Sohl LF, Bollmann JH, Borst JGG, Frotscher M, Sakmann B, Lubke JHR (2002) Three-dimensional reconstruction of a calyx of Held and its postsynaptic principal neuron in the medial nucleus of the trapezoid body. J Neurosci 22:10567-10579.

Saviane C, Savtchenko LP, Raffaelli G, Voronin LL, Cherubini E (2002) Frequency-dependent shift from paired-pulse facilitation to paired-pulse depression at unitary CA3-CA3 synapses in the rat hippocampus. J Physiol (Lond) 544:469-476.

Schikorski T, Stevens CF (1997) Quantitative ultrastructural analysis of hippocampal excitatory synapses. J Neurosci 17:5858-5867.

Schikorski T, Stevens CF (2001) Morphological correlates of functionally defined synaptic vesicle populations. Nat Neurosci 4:391-395.

Segal MM, Furshpan EJ (1990) Epileptiform activity in microcultures containing small numbers of hippocampal neurons. J Neurophysiol 64:1390-1399.

Silva AJ, Rosahl TW, Chapman PF, Marowitz Z, Friedman E, Frankland PW, Cestari V, Cioffi D, Südhof TC, Bourtchuladze R (1996) Impaired learning in mice with abnormal short-lived plasticity. Curr Biol 6:1509-1518. 
Sorensen JB, Nagy G, Varoqueaux F, Nehring RB, Brose N, Wilson MC, Neher E (2003) Differential control of the releasable vesicle pools by SNAP-25 splice variants and SNAP-23. Cell 114:75-86.

Südhof TC, Czernik AJ, Kao HT, Takei K, Johnston PA, Horiuchi A, Kanazir SD, Wagner MA, Perin MS, De Camilli P (1989) Synapsins: mosaics of shared and individual domains in a family of synaptic vesicle phosphoproteins. Science 245:1474-1480.

Terada S, Tsujimoto T, Takei Y, Takahashi T, Hirokawa N (1999) Impairment of inhibitory synaptic transmission in mice lacking synapsin I. J Cell Biol 145:1039-1048.

Thio LL, Yamada KA (2004) Differential presynaptic modulation of excitatory and inhibitory autaptic currents in cultured hippocampal neurons. Brain Res 1012:22-28.

Turrigiano GG, Nelson SB (2004) Homeostatic plasticity in the developing nervous system. Nat Rev Neurosci 5:97-107.

Verderio C, Pozzi D, Pravettoni E, Inverardi F, Schenk U, Coco S, Proux-
Gillardeaux V, Galli T, Rossetto O, Frassoni C, Matteoli M (2004) SNAP-25 modulation of calcium dynamics underlies differences in GABAergic and glutamatergic responsiveness to depolarization. Neuron 41:599-610.

Wesseling JF, Lo DC (2002) Limit on the role of activity in controlling the release-ready supply of synaptic vesicles. J Neurosci 22:9708-9720.

Wong AYC, Graham BP, Billups B, Forsythe ID (2003) Distinguishing between presynaptic and postsynaptic mechanisms of short-term depression during action potential trains. J Neurosci 23:4868-4877.

Wong-Riley M (1979) Changes in the visual system of monocularly sutured or enucleated cats demonstrable with cytochrome oxidase histochemistry. Brain Res 171:11-28.

Zhou Q, Petersen CCH, Nicoll RA (2000) Effects of reduced vesicular filling on synaptic transmission in rat hippocampal neurones. J Physiol (Lond) 525:195-206.

Zucker RS, Regehr WG (2002) Short-term synaptic plasticity. Annu Rev Physiol 64:355-405. 